\title{
Peripheral pure ground-glass opacity: segmentectomy versus wedge resection
}

\author{
Taobo Luo ${ }^{1,2 \dagger}$, Qixun Chen ${ }^{1,2 \dagger}$, Jian Zeng ${ }^{1,2^{*}}$, Lei Cai ${ }^{1,2}$ and Xiancong Huang ${ }^{1,2}$
}

\begin{abstract}
Introduction: Sublobar resection has been widely accepted for treating pure ground-glass opacities (GGOs). As GGOs have good prognosis, preserving postoperative pulmonary function is the major concern in surgery. No studies have yet compared the success rates of pulmonary function reservation between segmentectomy and wedge resection.
\end{abstract}

Method: The three-dimensional rebuild of computed tomography (CT) images was performed, the segmentectomy and wedge resection of the GGO in the target segment were simulated, and the area of cut surface was measured, which was important data for successful postoperative pulmonary recruitment maneuvers.

Result: With equal volumes of tissue removed, segmentectomy and wedge resection showed similar surface area loss for RS4 and RS5, followed by LS7 + 8, LS6 and LS1 + 2 segments. Compared with other segments, wedge resection performed in RS10, LS3, LS10, RS9 and RS7 may lead to a loss of lot more surface area than segmentectomy.

Conclusion: Wedge resection is suggested for segments RS4, RS5, LS1 +2 and LS7 + 8, whereas segmentectomy is advised for segments RS1, LS4 + 5 and RS2. Meanwhile, deep wedge resection should be avoided for segments RS8, RS7, RS10, LS3, LS10. RS9 and LS9, in order to preserve a larger lung surface area.

Keywords: Peripheral ground-glass opacity, Segmentectomy, Wedge resection, Surface area

\section{Introduction}

With the increasing acceptance of routine computed tomography (CT) screenings, early-stage lung cancer detection is also becoming more frequent. Groundglass opacities or GGOs are among lung cancers [1]. The persistent presence of a GGO nodule usually suggests the diagnosis of atypical adenomatous hyperplasia (AAH), adenocarcinoma in situ (AIS), or malignancies such as minimally invasive adenocarcinoma (MIA), or lepidic-predominant invasive adenocarcinomas (LPA) $[2,3]$. Pathological diagnosis is highly correlated with

\footnotetext{
*Correspondence: 68640770@qq.com

†Taobo Luo and Qixun Chen contributed equally to this work and should be considered co-first authors.

${ }^{1}$ Department of Thoracic Surgery, Cancer Hospital of The University of Chinese Academy of Sciences (Zhejiang Cancer Hospital), 1\# East Banshan Road, Hangzhou 310022, Zhejiang, China

Full list of author information is available at the end of the article
}

imaging manifestations [4], and the management of GGO depends on the overall size and existence of a solid component [5].

Surgical excision is optional for pure GGOs up to $5 \mathrm{~mm}$ if they are increasing in size and for pure GGOs larger than $10 \mathrm{~mm}$ that remain stable but are persistent [6]. The surgical strategy for treatment, however, remains controversial. Lobectomy and lymphadenectomy are classical surgical approaches for lung cancer. Compared with traditional lung cancer, GGOs, especially pure GGOs show relatively benign biological behavior. It is not currently clear whether lobectomy is still necessary to achieve a "radical" resection of GGOs. In this respect, a series of studies comparing sublobar resection and lobectomy were published. National Comprehensive Cancer Network (NCCN) guidelines have suggested that sublobar resection could be applied for peripheral nodule $\leq 2 \mathrm{~cm}$ with at least one of the original author(s) and the source, provide a link to the Creative Commons licence, and indicate if changes were made. The images or other third party material in this article are included in the article's Creative Commons licence, unless indicated otherwise in a credit line to the material. If material is not included in the article's Creative Commons licence and your intended use is not permitted by statutory regulation or exceeds the permitted use, you will need to obtain permission directly from the copyright holder. To view a copy of this licence, visit http://creativecommons.org/licenses/by/4.0/. The Creative Commons Public Domain Dedication waiver (http://creativeco mmons.org/publicdomain/zero/1.0/) applies to the data made available in this article, unless otherwise stated in a credit line to the data. 
following criteria: pure AIS histology; nodule has $\geq 50 \%$ ground-glass appearance on CT; radiologic surveillance confirms a long doubling time ( $\geq 400$ days).

Nevertheless, only a few studies have focused on the comparison of different approaches of sublobar resection. Previous researches [7-9] compared segmentectomy and wedge resection for all stage I or IA non-small-cell lung cancer (NSCLC) cases, and their main endpoints were overall survival (OS) and diseasefree survival (DFS). For GGOs, especially pure GGOs, OS and DFS make little sense as they consist a relatively benign biological behavior, thus the aim to reserve more pulmonary function when the margin is sufficient may be a more meaningful approach. Since no studies have addressed this subject, the application of segmentectomy and wedge resection in peripheral pure GGOs remain controversial.

Successful lung recruitment maneuvers are closely associated with postoperative pulmonary function recovery. This process is mainly affected by two factors: the negative intrathoracic pressure and the surface area of residual lung. Therefore, for a given volume of removed lung tissue, the surgical approach that could leave more surface area brings more advantage for pulmonary function retention. This paper attempts to theoretically analyze the surface area loss caused by sublobar resection of peripheral small GGOs located in each segment using a three-dimensional rebuild of $\mathrm{CT}$ images, in order to provide more evidence for a better choice of surgical approach for sublobar resection.

\section{Methods}

The study used the database of our medical center to analyze CT images of 241 patients with peripheral pure GGO(s) located in different segments. There were 15 patients for each segment (some patients have multiple GGOs in different segments). The images were in CT-DICOM format, had layer thickness $\leq 1.25 \mathrm{~mm}$ and were scans from apex pulmonis to basis pulmonis. All patients signed a written informed consent during their hospital stay.

The DICOM images were imported into 3DSlicer software, which rebuilds the complete three-dimensional model from two-dimensional slices, and conducts measurement, labeling, segmentation and other operations on the obtained model. Different segments depending on the tracheal distribution were identified and the volume and surface area of different segments and the whole lung were measured. Next, segmentectomy and wedge resection for GGO in the target segments were simulated, and the area of resected surface was measured.

\section{Results}

For each segment, we select a typical patient to show detailed three-dimensional model and calculation process.

\section{Right superior lobe, apical segment (RS1)}

The whole right superior lobe of patient 1 has a volume of $589,588.24 \mathrm{~mm}^{3}$, and a surface area of $44,284.03 \mathrm{~mm}^{2}$. The volume and surface area of RS1 are $169,714.31 \mathrm{~mm}^{3}$ and $11,871.71 \mathrm{~mm}^{2}$, respectively (Fig. 1).

Segmentectomy of RS1 will leave a cut surface of $6128.09 \mathrm{~mm}^{2}$, which means a surface loss of 5743.62 $\mathrm{mm}^{2}$. As the intersegmental plane is separated with electric scalpel and ultrasonic knife only and no cut surface compression is practical, the $5743.62 \mathrm{~mm}^{2}$ is regarded as accessible.

With equal volume of tissue removed, wedge resection will theoretically leave a cut surface of 6032.29 $\mathrm{mm}^{2}$. In practice, linear cutters are used, and the whole cut surface is stapled. Thus, the cut surface loss comprises the whole preoperative surface area of the target region, measuring $12,570.69 \mathrm{~mm}^{2}$.

\section{Right superior lobe, posterior segment (RS2)}

The whole right superior lobe of patient 2 has a volume of $944,915.50 \mathrm{~mm}^{3}$, and a surface area of $60,584.28 \mathrm{~mm}^{2}$. The volume and surface area of RS2 are $216,119.51 \mathrm{~mm}^{3}$ and $15,085.19 \mathrm{~mm}^{2}$, respectively (Fig. 2).

Segmentectomy of RS2 will leave a cut surface of $8402.69 \mathrm{~mm}^{2}$, which means a surface loss of 6682.50 $\mathrm{mm}^{2}$. With equal volume of tissue removed, wedge resection will theoretically leave a cut surface of $8689.07 \mathrm{~mm}^{2}$. In practice, the cut surface loss comprises the whole preoperative surface area of the target region, measuring $15,979.69 \mathrm{~mm}^{2}$.

\section{Right superior lobe, anterior segment (RS3)}

The whole right superior lobe of patient 3 has a volume of $797,442.34 \mathrm{~mm}^{3}$, and a surface area of $53,681.25 \mathrm{~mm}^{2}$. The volume and surface area of RS3 are $289,249.96 \mathrm{~mm}^{3}$ and $21,583.15 \mathrm{~mm}^{2}$, respectively (Fig. 3).

Segmentectomy of RS3 will leave a cut surface of $7420.26 \mathrm{~mm}^{2}$, which means a surface loss of $14,162.89$ $\mathrm{mm}^{2}$. With equal volume of tissue removed, wedge 


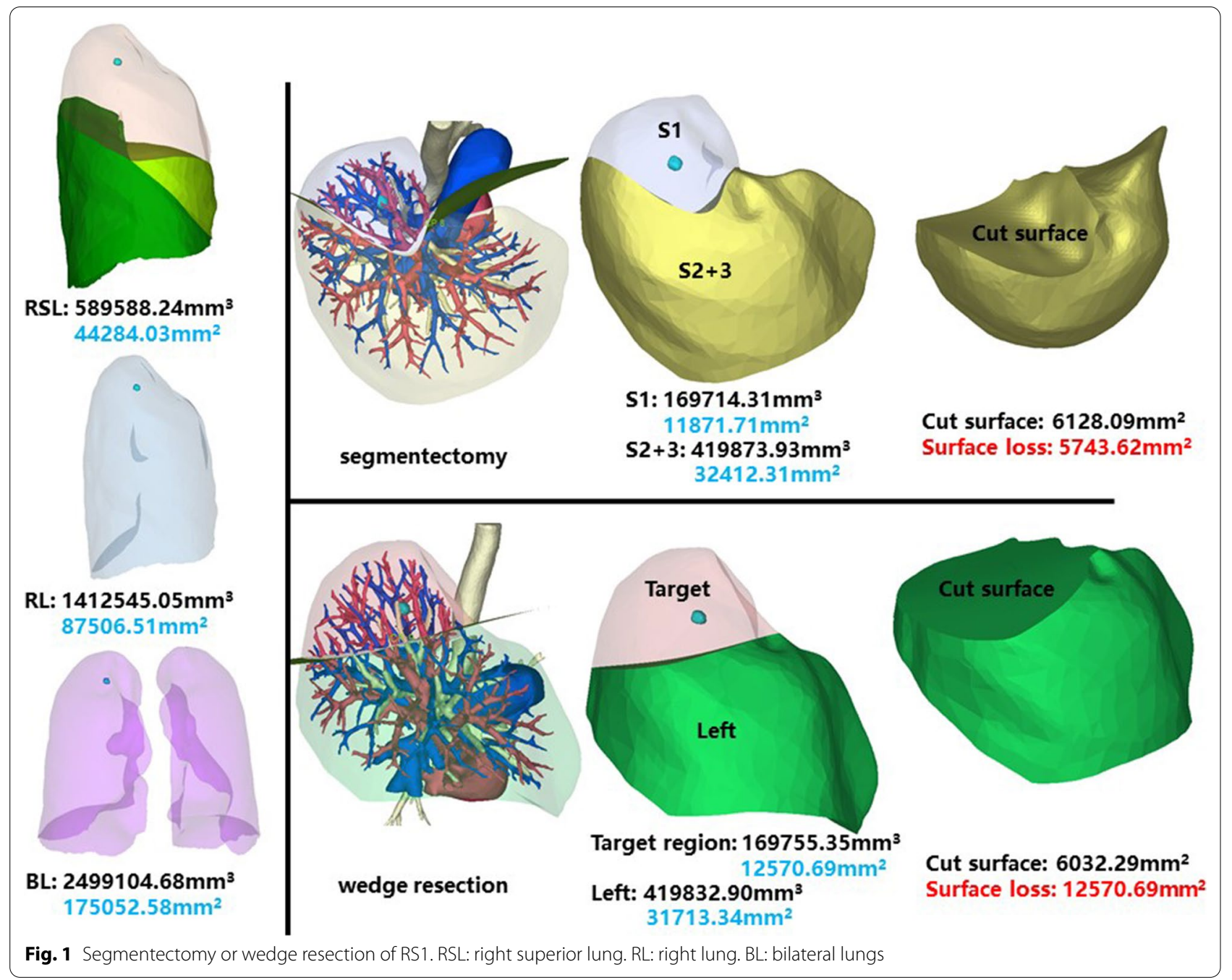

resection will theoretically leave a cut surface of $5644.37 \mathrm{~mm}^{2}$. In practice, the cut surface loss comprises the whole preoperative surface area of the target region, measuring $22,528.32 \mathrm{~mm}^{2}$.

\section{Right middle lobe, lateral segment (RS4)}

The whole right middle lobe of patient 4 has a volume of $417,643.84 \mathrm{~mm}^{3}$, and a surface area of $40,877.08 \mathrm{~mm}^{2}$. The volume and surface area of RS4 are 142,238.29 $\mathrm{mm}^{3}$ and $15,121.78 \mathrm{~mm}^{2}$, respectively (Fig. 4).

Segmentectomy of RS4 will leave a cut surface of $4875.00 \mathrm{~mm}^{2}$, which means a surface loss of $10,246.78$ $\mathrm{mm}^{2}$. With equal volume of tissue removed, wedge resection will theoretically leave a cut surface of $4001.63 \mathrm{~mm}^{2}$. In practice, the cut surface loss comprises the whole preoperative surface area of the target region, measuring $14,203.62 \mathrm{~mm}^{2}$.
Right middle lobe, medial segment (RS5)

The whole right middle lobe of patient 5 has a volume of $352,708.87 \mathrm{~mm}^{3}$, and a surface area of $41,255.94 \mathrm{~mm}^{2}$. The volume and surface area of RS5 are $223,184.36 \mathrm{~mm}^{3}$ and 21,259.91 $\mathrm{mm}^{2}$, respectively (Fig. 5).

Segmentectomy of RS5 will leave a cut surface of $3695.87 \mathrm{~mm}^{2}$, which means a surface loss of $17,564.04$ $\mathrm{mm}^{2}$. With equal volume of tissue removed, wedge resection will theoretically leave a cut surface of $4027.12 \mathrm{~mm}^{2}$. In practice, the cut surface loss comprises the whole preoperative surface area of the target region, measuring $21,471.79 \mathrm{~mm}^{2}$.

\section{Right inferior lobe, dorsal segment (RS6)}

This segment is of the same patient as RS5. The whole right inferior lobe of patient 5 has a volume of 952,355.97 $\mathrm{mm}^{3}$, and a surface area of 73,760.92 $\mathrm{mm}^{2}$. The 


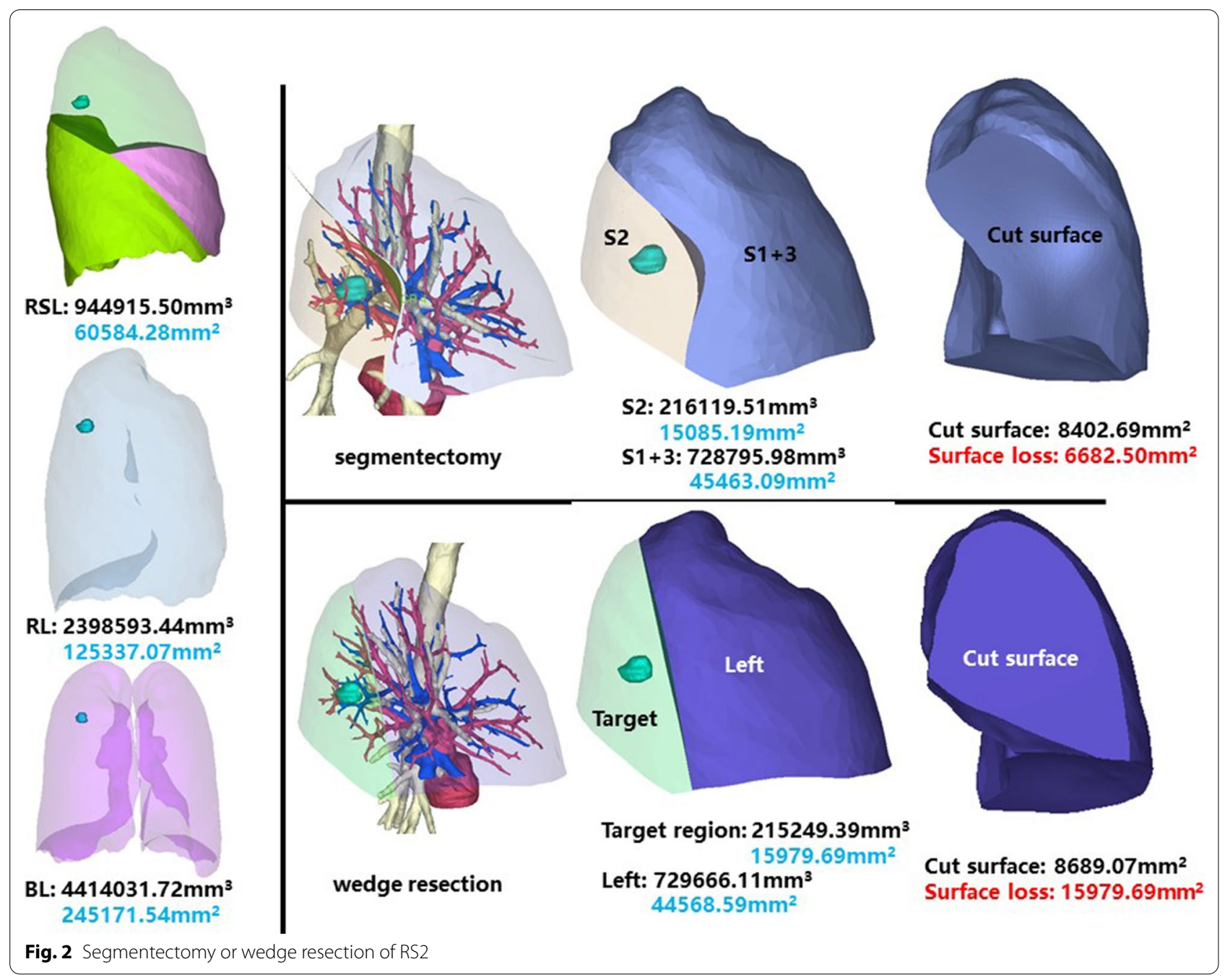

volume and surface area of RS6 are $264,113.24 \mathrm{~mm}^{3}$ and 20,503.96 $\mathrm{mm}^{2}$, respectively (Fig. 6).

Segmentectomy of RS6 will leave a cut surface of $7110.72 \mathrm{~mm}^{2}$, which means a surface loss of $13,393.24$ $\mathrm{mm}^{2}$. With equal volume of tissue removed, wedge resection will theoretically leave a cut surface of $6846.52 \mathrm{~mm}^{2}$. In practice, the cut surface loss comprises the whole preoperative surface area of the target region, measuring $20,794.13 \mathrm{~mm}^{2}$.

\section{Right inferior lobe, medial basal segment (RS7)}

The whole right inferior lobe of patient 6 has a volume of $1,842,607.70 \mathrm{~mm}^{3}$, and a surface area of $108,791.86 \mathrm{~mm}^{2}$. The volume and surface area of RS7 are $188,331.19 \mathrm{~mm}^{3}$ and $14,705.79 \mathrm{~mm}^{2}$, respectively (Fig. 7).

Segmentectomy of RS7 will leave a cut surface of $9760.64 \mathrm{~mm}^{2}$, which means a surface loss of 4945.15 $\mathrm{mm}^{2}$. With equal volume of tissue removed, wedge resection will theoretically leave a cut surface of $9879.26 \mathrm{~mm}^{2}$. In practice, the cut surface loss comprises the whole preoperative surface area of the target region, measuring $22,199.1 \mathrm{~mm}^{2}$.

Right inferior lobe, anterior basal segment (RS8)

The whole right inferior lobe of patient 7 has a volume of $1,000,065.57 \mathrm{~mm}^{3}$, and a surface area of $69,733.93 \mathrm{~mm}^{2}$. The volume and surface area of RS8 are $192,000.37 \mathrm{~mm}^{3}$ and $16,612.40 \mathrm{~mm}^{2}$, respectively (Fig. 8).

Segmentectomy of RS8 will leave a cut surface of 8509.04 $\mathrm{mm}^{2}$, which means a surface loss of $8103.36 \mathrm{~mm}^{2}$. With equal volume of tissue removed, wedge resection will theoretically leave a cut surface of $7962.64 \mathrm{~mm}^{2}$. In practice, the cut surface loss comprises the whole preoperative surface area of the target region, measuring $15,856.85 \mathrm{~mm}^{2}$. 


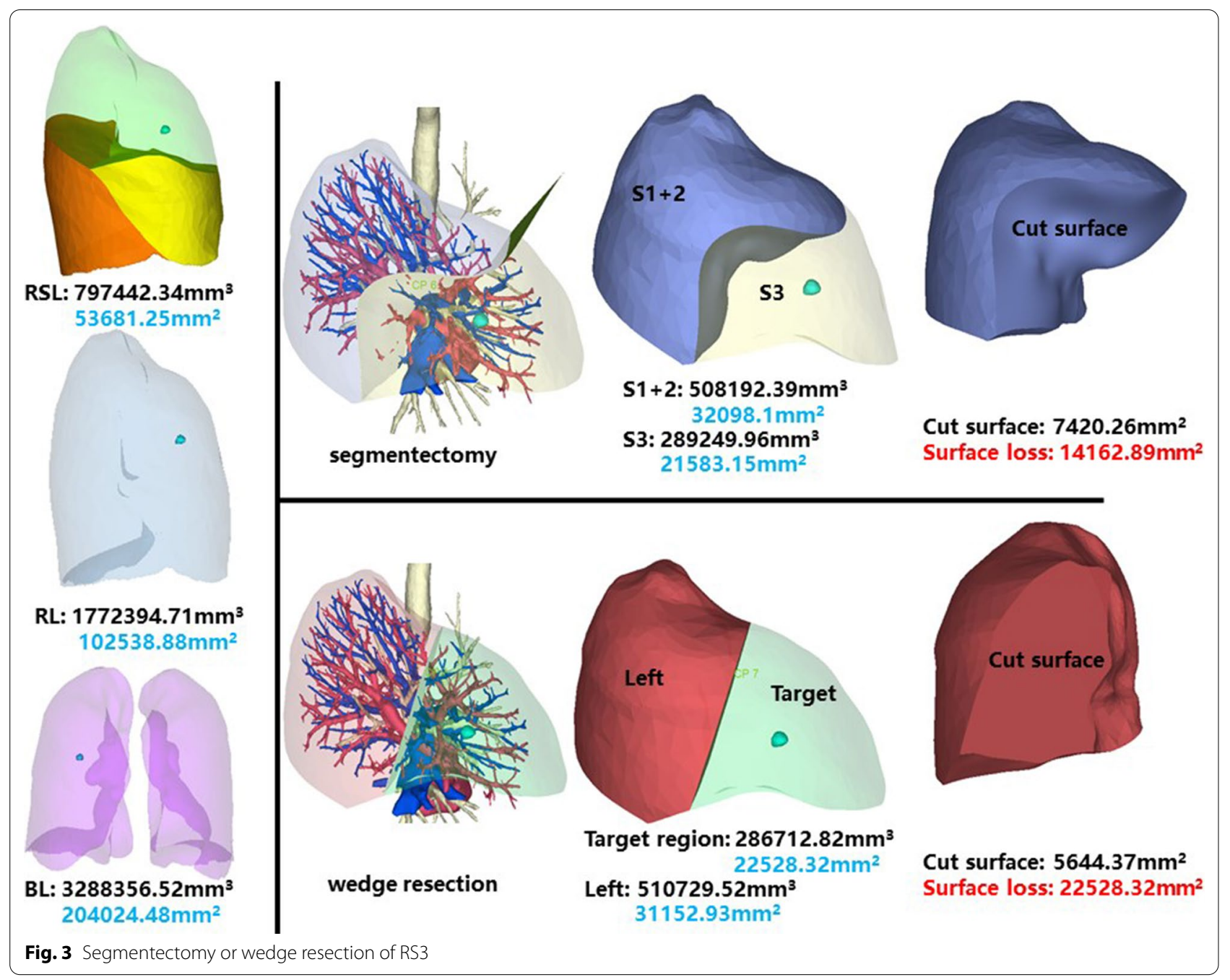

\section{Right inferior lobe, lateral basal segment (RS9)}

The whole right inferior lobe of patient 8 has a volume of $997,941.56 \mathrm{~mm}^{3}$, and a surface area of $69,635.33 \mathrm{~mm}^{2}$. The volume and surface area of RS9 are $211,224.35 \mathrm{~mm}^{3}$ and $10,817.54 \mathrm{~mm}^{2}$, respectively (Fig. 9).

Segmentectomy of RS9 will leave a cut surface of $14,404.05 \mathrm{~mm}^{2}$, which means a surface loss of $10,817.54 \mathrm{~mm}^{2}$. With equal volume of tissue removed, wedge resection will theoretically leave a cut surface of $7054.46 \mathrm{~mm}^{2}$. In practice, the cut surface loss comprises the whole preoperative surface area of the target region, measuring $23,606.32 \mathrm{~mm}^{2}$.

\section{Right inferior lobe, posterior basal segment (RS10)}

The whole right inferior lobe of patient 9 has a volume of $952,355.97 \mathrm{~mm}^{3}$, and a surface area of
$73,760.92 \mathrm{~mm}^{2}$. The volume and surface area of RS10 are $261,996.57 \mathrm{~mm}^{3}$ and $17,645.4 \mathrm{~mm}^{2}$, respectively (Fig. 10).

Segmentectomy of RS10 will leave a cut surface of $12,857.49 \mathrm{~mm}^{2}$, which means a surface loss of 4787.91 $\mathrm{mm}^{2}$. With equal volume of tissue removed, wedge resection will theoretically leave a cut surface of $8140.21 \mathrm{~mm}^{2}$. In practice, the cut surface loss comprises the whole preoperative surface area of the target region, measuring $23,909.18 \mathrm{~mm}^{2}$.

\section{Left superior lobe, posterior apical segment (LS1 + 2)}

The whole left superior lobe of patient 10 has a volume of $713,994.38 \mathrm{~mm}^{3}$, and a surface area of $55,415.31$ $\mathrm{mm}^{2}$. The volume and surface area of LS1 +2 are $264,710.44 \mathrm{~mm}^{3}$ and $19,469.77 \mathrm{~mm}^{2}$, respectively (Fig. 11). 


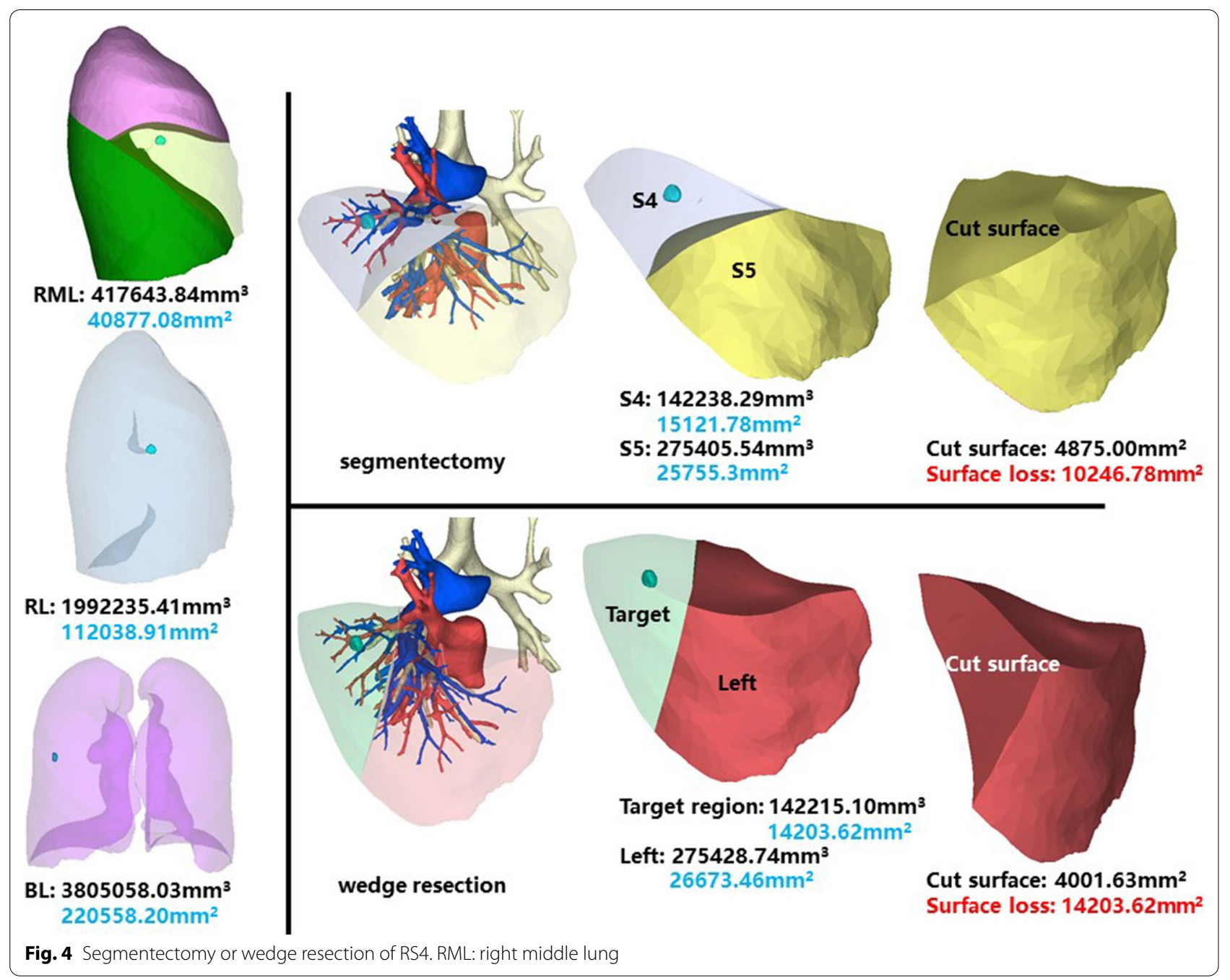

Segmentectomy of $\mathrm{LS} 1+2$ will leave a cut surface of $5421.55 \mathrm{~mm}^{2}$, which means a surface loss of $14,047.45 \mathrm{~mm}^{2}$. With equal volume of tissue removed, wedge resection will theoretically leave a cut surface of $4808.27 \mathrm{~mm}^{2}$. In practice, the cut surface loss comprises the whole preoperative surface area of the target region, measuring $18,947.56 \mathrm{~mm}^{2}$.

\section{Left superior lobe, anterior segment (LS3)}

The whole left superior lobe of patient 11 has a volume of $473,283.99 \mathrm{~mm}^{3}$, and a surface area of $45,858.58 \mathrm{~mm}^{2}$. The volume and surface area of LS3 are $207,339.74 \mathrm{~mm}^{3}$ and $17,465.85 \mathrm{~mm}^{2}$, respectively (Fig. 12).

Segmentectomy of LS3 will leave a cut surface of $6663.27 \mathrm{~mm}^{2}$, which means a surface loss of $10,802.58$ $\mathrm{mm}^{2}$. With equal volume of tissue removed, wedge resection will theoretically leave a cut surface of $4500.27 \mathrm{~mm}^{2}$. In practice, the cut surface loss comprises the whole preoperative surface area of the target region, measuring $22,581.38 \mathrm{~mm}^{2}$.

\section{Left superior lobe, lingual segment (LS4+5)}

This segment is of the same patient as LS1+2. The volume and surface area of LS4 +5 are $246,737.91 \mathrm{~mm}^{3}$ and $24,337.37 \mathrm{~mm}^{2}$, respectively (Fig. 13).

Segmentectomy of LS4+5 will leave a cut surface of $5546.14 \mathrm{~mm}^{2}$, which means a surface loss of $18,791.23 \mathrm{~mm}^{2}$. With equal volume of tissue removed, wedge resection will theoretically leave a cut surface of $5695.08 \mathrm{~mm}^{2}$. In practice, the cut surface loss comprises the whole preoperative surface area of the target region, measuring $25,654.26 \mathrm{~mm}^{2}$. 


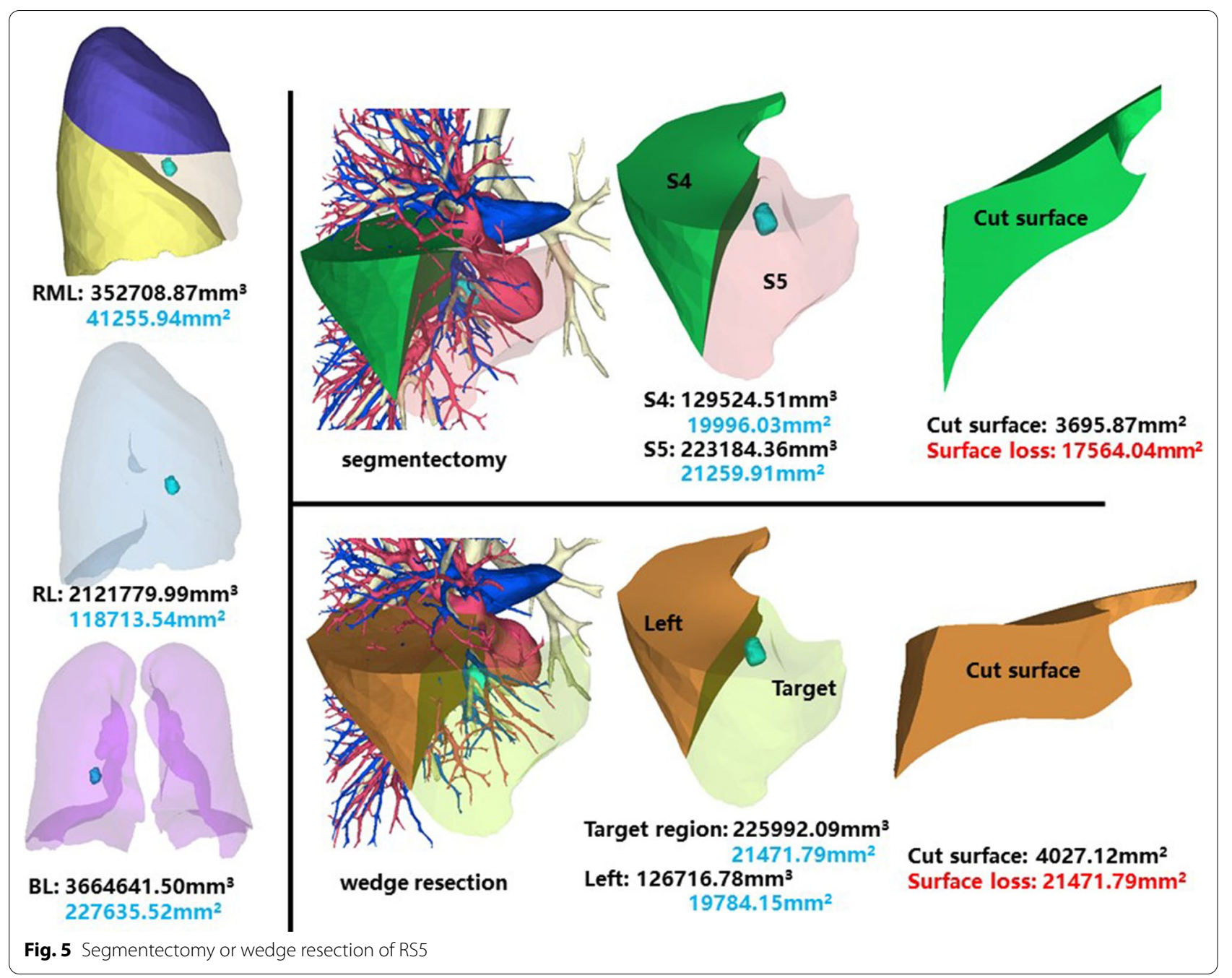

\section{Left inferior lobe, dorsal segment (LS6)}

The whole left inferior lobe of patient 12 has a volume of 1,645,078.99 $\mathrm{mm}^{3}$, and a surface area of $102,286.62 \mathrm{~mm}^{2}$. The volume and surface area of LS6 are $373,466.25 \mathrm{~mm}^{3}$ and $26,738.56 \mathrm{~mm}^{2}$, respectively (Fig. 14).

Segmentectomy of LS6 will leave a cut surface of $9204.92 \mathrm{~mm}^{2}$, which means a surface loss of $17,533.64$ $\mathrm{mm}^{2}$. With equal volume of tissue removed, wedge resection will theoretically leave a cut surface of $9854.18 \mathrm{~mm}^{2}$. In practice, the cut surface loss comprises the whole preoperative surface area of the target region, measuring $25,672.09 \mathrm{~mm}^{2}$.

Left inferior lobe, medial anterior basal segment (LS7+8) The whole left inferior lobe of patient 13 has a volume of $1,127,974.89 \mathrm{~mm}^{3}$, and a surface area of $78,139.65$ $\mathrm{mm}^{2}$. The volume and surface area of LS7 +8 are $382,103.60 \mathrm{~mm}^{3}$ and $29,760.10 \mathrm{~mm}^{2}$, respectively (Fig. 15).

Segmentectomy of LS7 +8 will leave a cut surface of $8528.72 \mathrm{~mm}^{2}$, which means a surface loss of $21,231.38 \mathrm{~mm}^{2}$. With equal volume of tissue removed, wedge resection will theoretically leave a cut surface of $7610.04 \mathrm{~mm}^{2}$. In practice, the cut surface loss comprises the whole preoperative surface area of the target region, measuring $27,431.54 \mathrm{~mm}^{2}$.

Left inferior lobe, lateral anterior basal segment (LS9) The whole left inferior lobe of patient 14 has a volume of $991,727.55 \mathrm{~mm}^{3}$, and a surface area of $75,348.86 \mathrm{~mm}^{2}$. The volume and surface area of LS9 are $290,339.57 \mathrm{~mm}^{3}$ and $15,589.33 \mathrm{~mm}^{2}$, respectively (Fig. 16). 


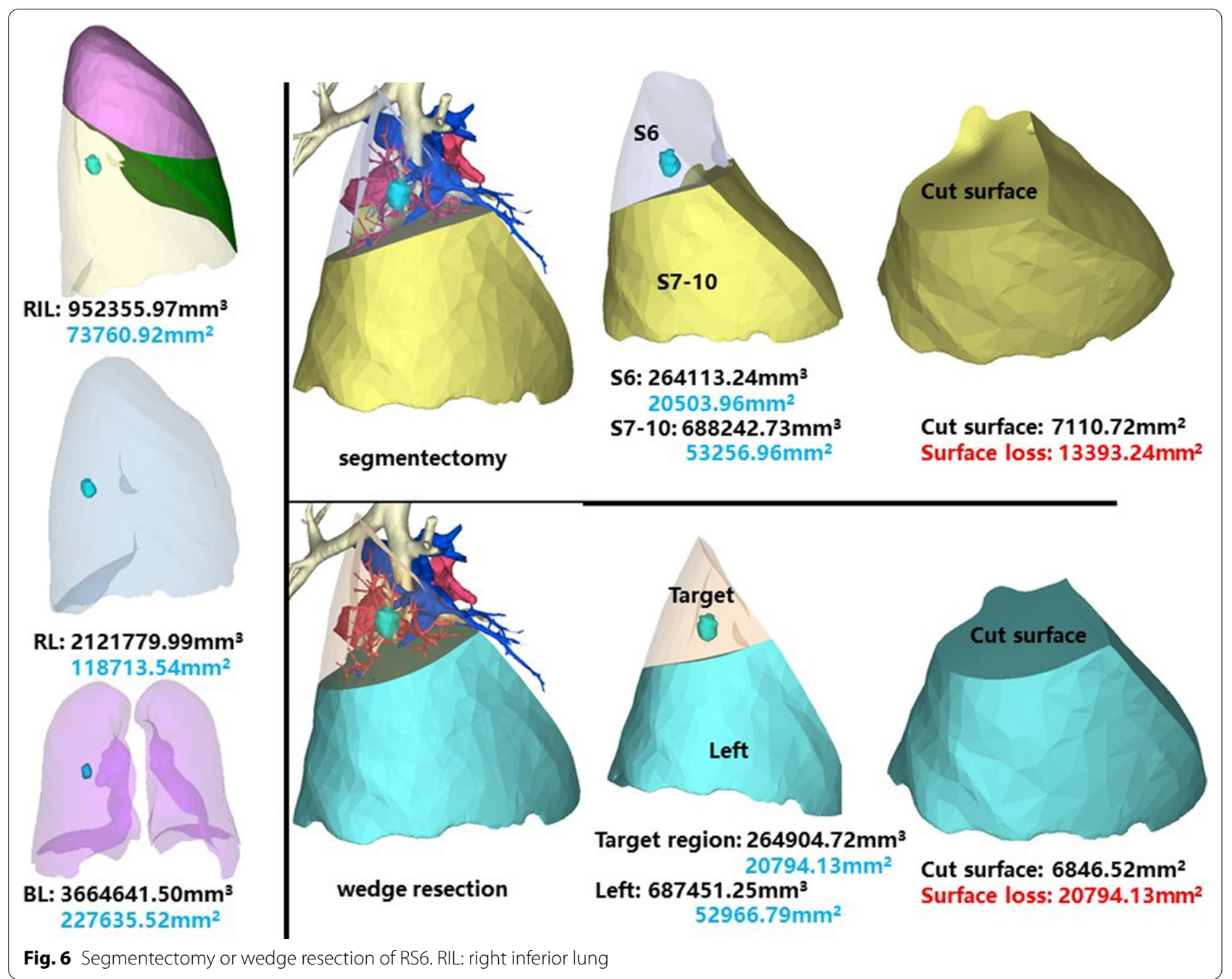

Segmentectomy of LS9 will leave a cut surface of $17,786.52 \mathrm{~mm}^{2}$, which means a surface loss of $15,589.33$ $\mathrm{mm}^{2}$. With equal volume of tissue removed, wedge resection will theoretically leave a cut surface of $8799.63 \mathrm{~mm}^{2}$. In practice, the cut surface loss comprises the whole preoperative surface area of the target region, measuring $27,346.75 \mathrm{~mm}^{2}$.

\section{Left inferior lobe, posterior basal segment (LS10)}

This segment is of the same patient as LS7 +8 . The volume and surface area of LS10 are 403,290.84 $\mathrm{mm}^{3}$ and $26,251.11 \mathrm{~mm}^{2}$, respectively (Fig. 17).

Segmentectomy of LS10 will leave a cut surface of $10,706.52 \mathrm{~mm}^{2}$, which means a surface loss of $15,544.59$ $\mathrm{mm}^{2}$. With equal volume of tissue removed, wedge resection will theoretically leave a cut surface of 10,128.75 $\mathrm{mm}^{2}$. In practice, the cut surface loss comprises the whole preoperative surface area of target region, measuring $30,265.14 \mathrm{~mm}^{2}$.
For each of all of the segments, the mean difference value of the surface loss of all segments after simulation of segmentectomy and wedge resection of the 241 patients was calculated (Table 1). After converting the result into relative value of whole pulmonary surface area, it was found that both segments of right middle lobe showed an unobvious surface loss gap between the two approaches, followed by LS1 +2 and LS7 +8 . On the contrary, wedge resection performed in RS8, RS7, RS10, LS3, LS10. RS9 and LS9 segments may lead to much higher surface area loss than segmentectomy, as compared with other segments.

\section{Discussion}

Sublobar resection was previously the only alternative for patients that could not tolerate lobectomy. A prospective, multicenter randomized clinical trial showed that sublobar resection did not show any differences in perioperative complications, mortality, and 


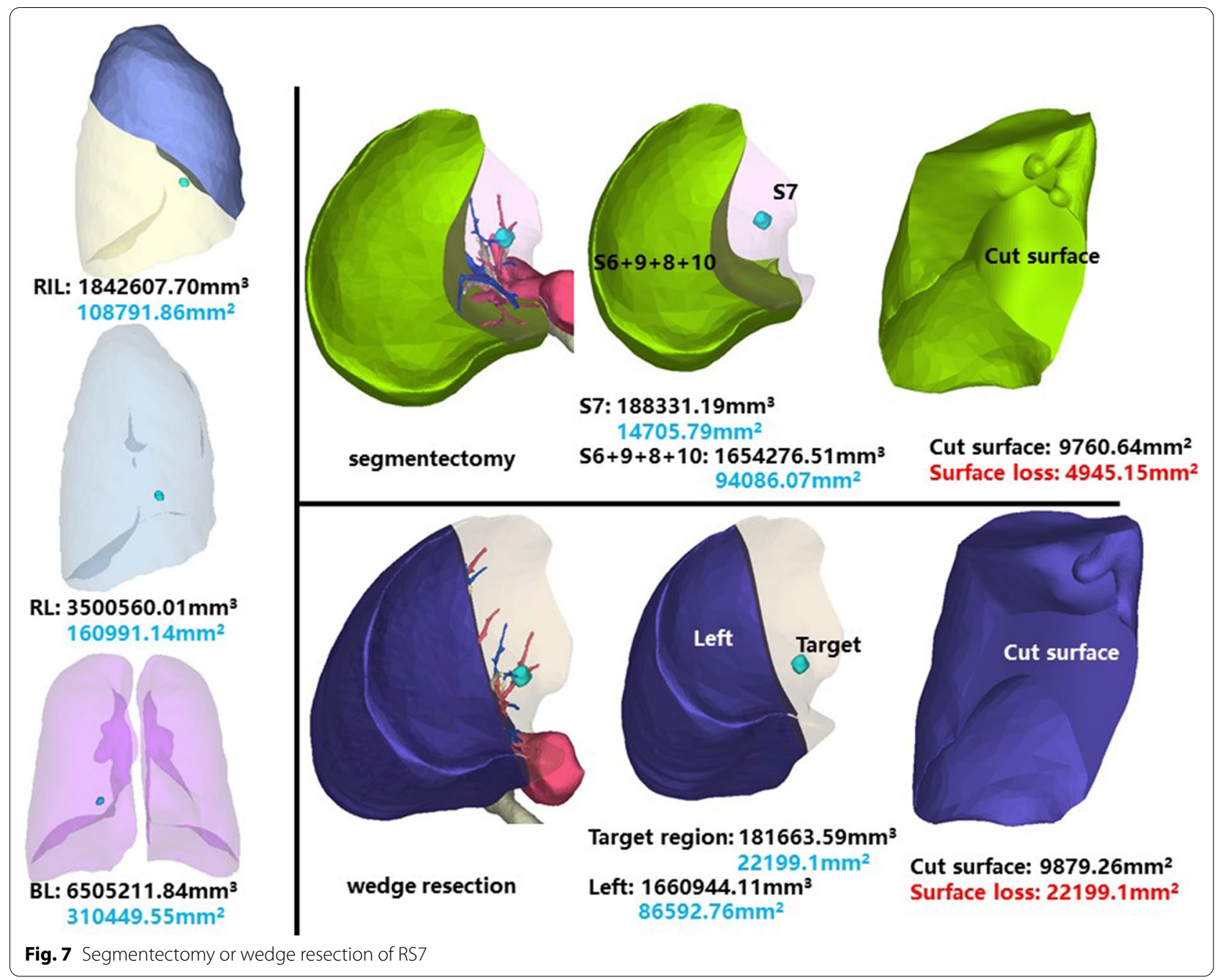

postoperative pulmonary function after lobectomy, but the recurrence rate was three times as high as that after lobectomy [10]. A different prospective, multicenter non-randomized clinical trial reported similar results, in that the sublobar resection group had a higher local recurrence rate, and the lobectomy group featured higher 5-year OS [11]. These well-known researches established lobectomy as a "golden standard" of surgical treatment for NSCLC. In recent years, with a growing number of patients presenting NSCLC with low potential malignancy, sublobar resection is returning to practice. In clinical work, most pure GGOs fit the NCCN criteria: pure AIS histology, nodule has $\geq 50 \%$ groundglass appearance on $\mathrm{CT}$, and radiologic surveillance confirms a long doubling time ( $\geq 400$ days). Therefore, the applicability of sublobar resection in patients with pure GGOs is widely accepted.

Regrettably, no studies have provided guidance on the choice of surgical approach for sublobar resection of pure
GGOs, as pulmonary function preservation has priority in pure GGO patients, unlike in those with solid nodules. For pure GGOs beneath the visceral pleura, simple wedge resection could achieve the treatment goal; for pure GGOs located near the segmental portal, segmentectomy is necessary; whereas for other peripheral pure GGOs, it is difficult to compare the resected pulmonary volume when margin is ensured. Therefore, we set a relatively "standard" model to make the comparisons.

Our model was set up based on following assumptions: a. segmentectomy and wedge resection affect equal pulmonary volumes; b. only power equipments (electric scalpel and ultrasonic knife) are used to separate the intersegmental plane (as linear cutters may be used in practice, this model only considers a fully stretched status of intersegmental plane); c. there is no adhesion in the thorax and the interlobar fissure develops well; $d$. the anatomical structure and volume distribution of all segments are standard without variation. 


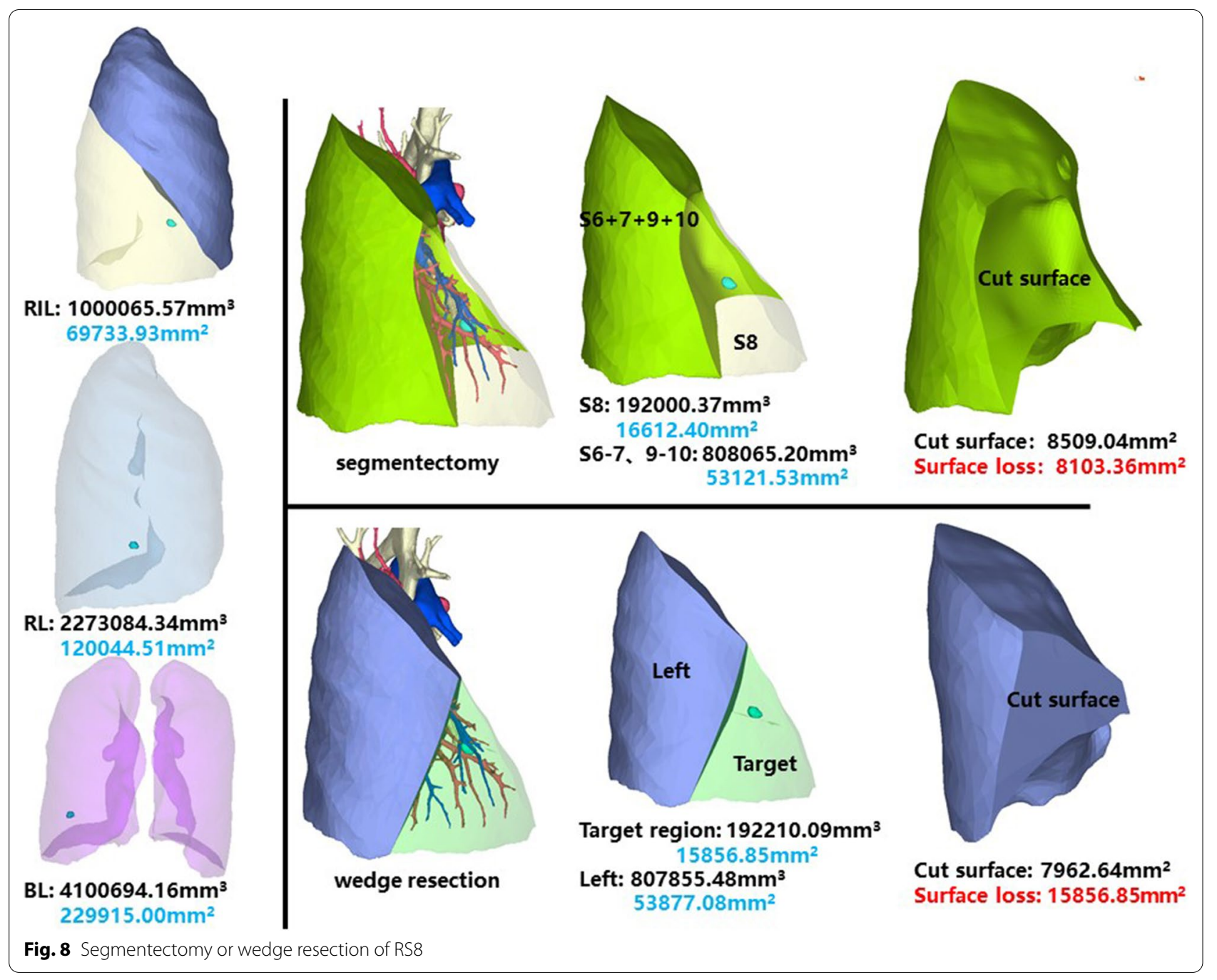

According to the three-dimensional reconstruction of CT images, different segments show significantly different surface loss values between segmentectomy and wedge resection. Regarding surface loss, it is the spatial structure and neighbouring relations of each segment that matter the most. Irregular and large-sized cut surface (e.g., RS10, LS3 and LS10) means more tissue compression needed to perform wedge resection with linear cutters, which corresponds to more surface loss. For a cut surface that is small and plane (e.g., RS4, RS5 and LS7 +8 ), wedge sections may be appropriate as surface loss is acceptable compared with segmentectomy. Surface loss has adverse effects on pulmonary recruitment, and induce postoperative pulmonary atelectasis, which is commonly seen in CT images after wedge resections, especially the wedge resection of S10. Segmentectomy can help to solve this issue. Following the segmentectomy of S10, well re-tensioned lungs can be seen without pulmonary atelectasis and shrivel in CT images, especially when the intersegmental plane is separated by power equipments only. Therefore, for segments RS4, RS5, $\mathrm{LS} 1+2$, LS6 and LS7 + 8, wedge resection is suggested; for segments RS1, RS2, RS6, RS8 and LS4+5, segmentectomy is suggested, and deep wedge resection should be avoided for segments RS7, RS9, RS10, LS3 and LS10, as a stapled cut surface will have huge impact on postoperative pulmonary recruitment.

In addition, most lung tissues removed by wedge resection are peripheral, which contain more alveolar tissue for gas exchange, while residual lung tissue has more airways and blood vessels for air and blood delivery. On the other hand, segmentectomy-resected alveolar tissue and the corresponding airways and blood vessels form a functional unit as a whole, and the residual lung tissue is still a unit of complete respiratory function. Therefore, wedge resection with disproportional removal of tissue types will have a more adverse impact on air exchange function compared with segmentectomy. 


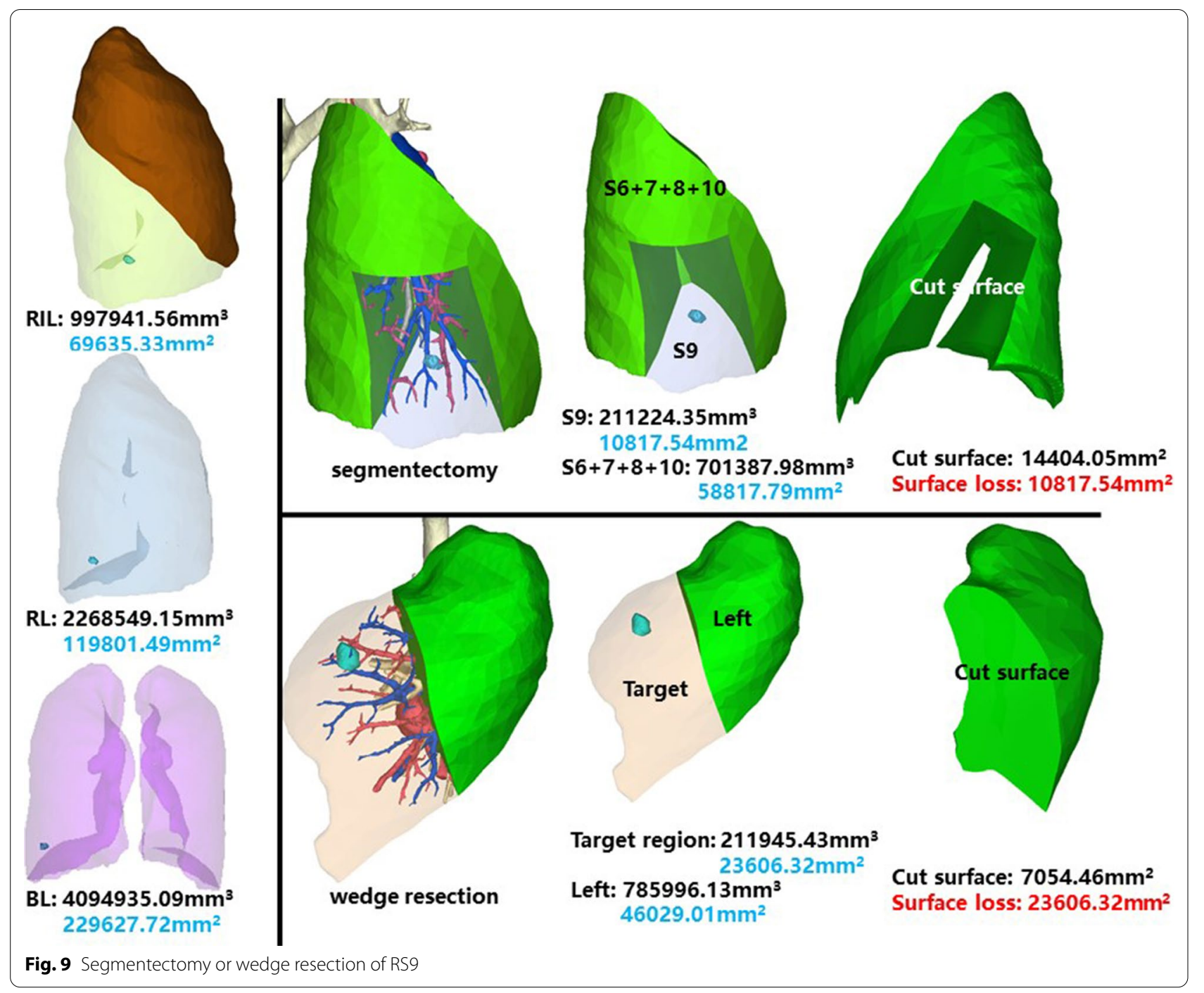

The present study has certain limitations and features worth noting. Firstly, it only targets pure GGOs that are peripheral, but still show a certain distance from the surface, which need a "deep" wedge resection to ensure the margin. Surgical procedures for such lesions are the most complex ones. Secondly, the volume of each segment differs between individuals, thus the volume and surface area of our model is not able to fit all situations. Thirdly, as intrathoracic adhesions, undeveloped interlobar fissure and hilar area are not correlated with pulmonary recruitment, they were not involved in our model. Fourthly, many thoracic surgeons use a stapler to separate part or all of the intersegmental plane, which still results in surface loss and neighboring segment compression. Therefore, from the perspective of pulmonary function reserve, it is suggested to separate the intersegmental plane in segmentectomy using power equipment only. On some occasions, wedge resection may be performed as nonlinear, which is not discussed in this article, either.

The conclusions drawn in this paper still need to be verified. Therefore, we look forward to the reporting of more convincing and robust data that could eventually resolve the controversy between segmentectomy and wedge resection.

\section{Conclusion}

Wedge resection is suggested for some certain segments, such as RS4, RS5, LS1 +2 and LS7 + 8, whereas segmentectomy is advised for segments RS1, LS4 +5 and RS2. Meanwhile, deep wedge resection should be avoided for segments RS8, RS7, RS10, LS3, LS10. RS9 and LS9, in order to preserve a larger lung surface area. 


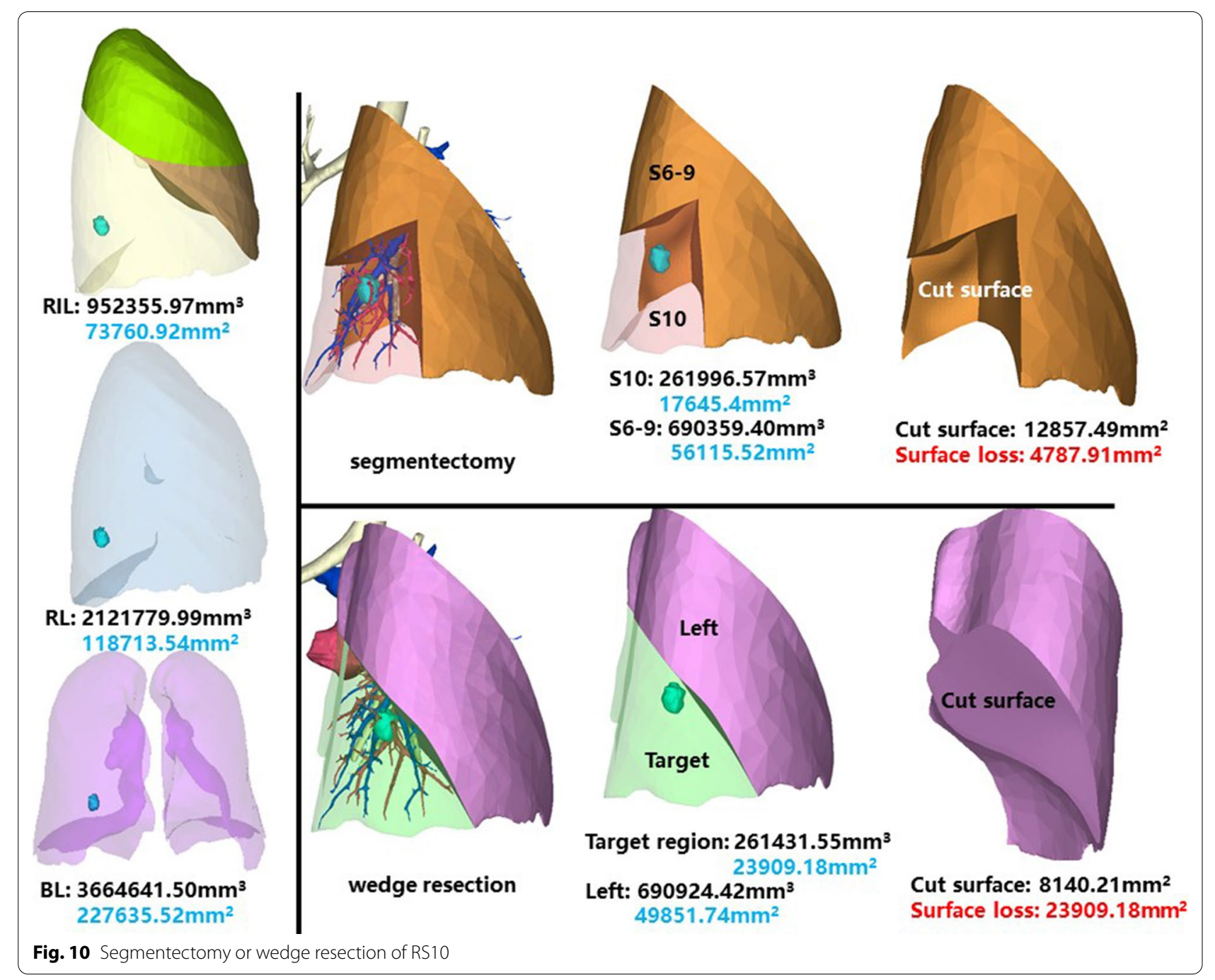




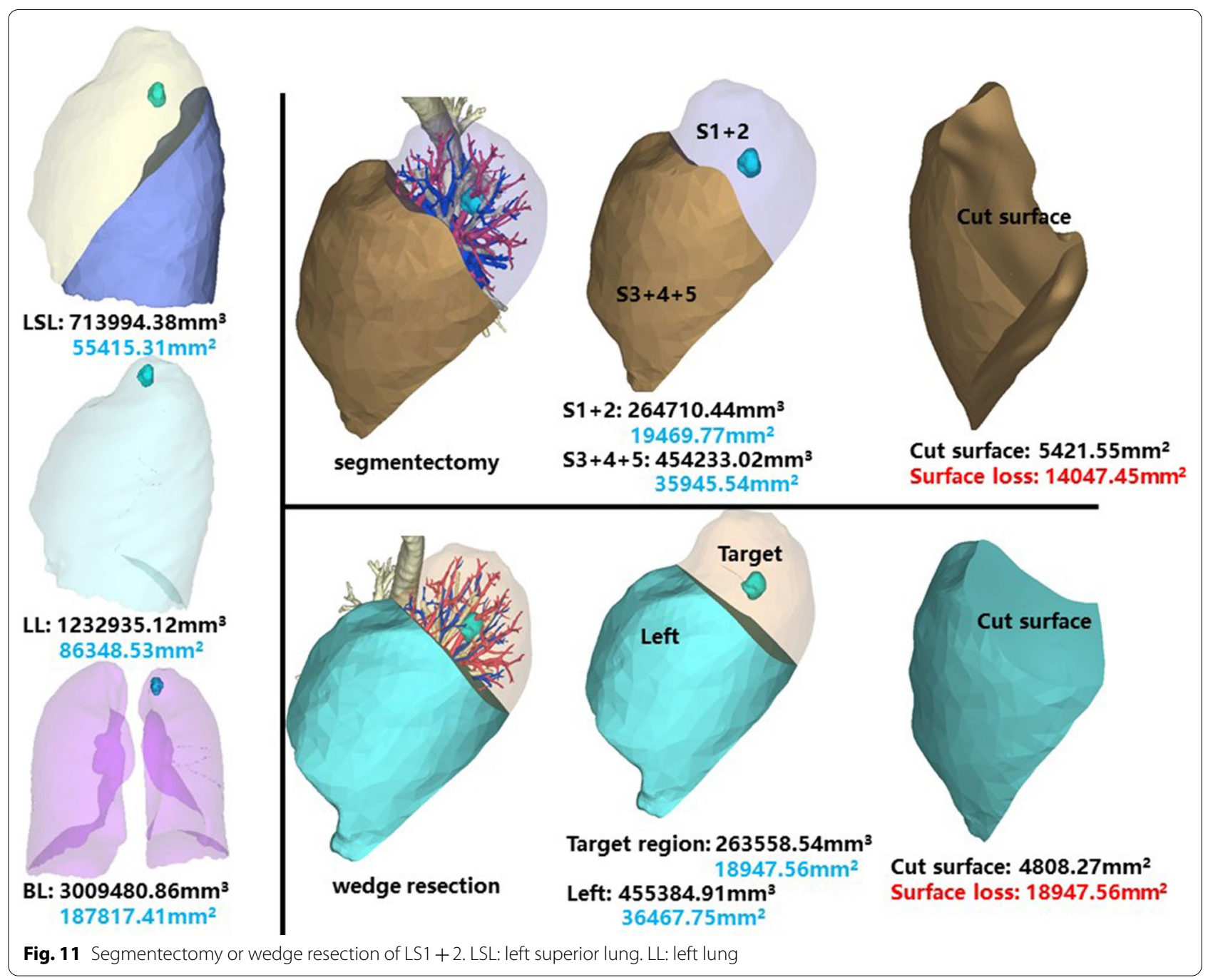




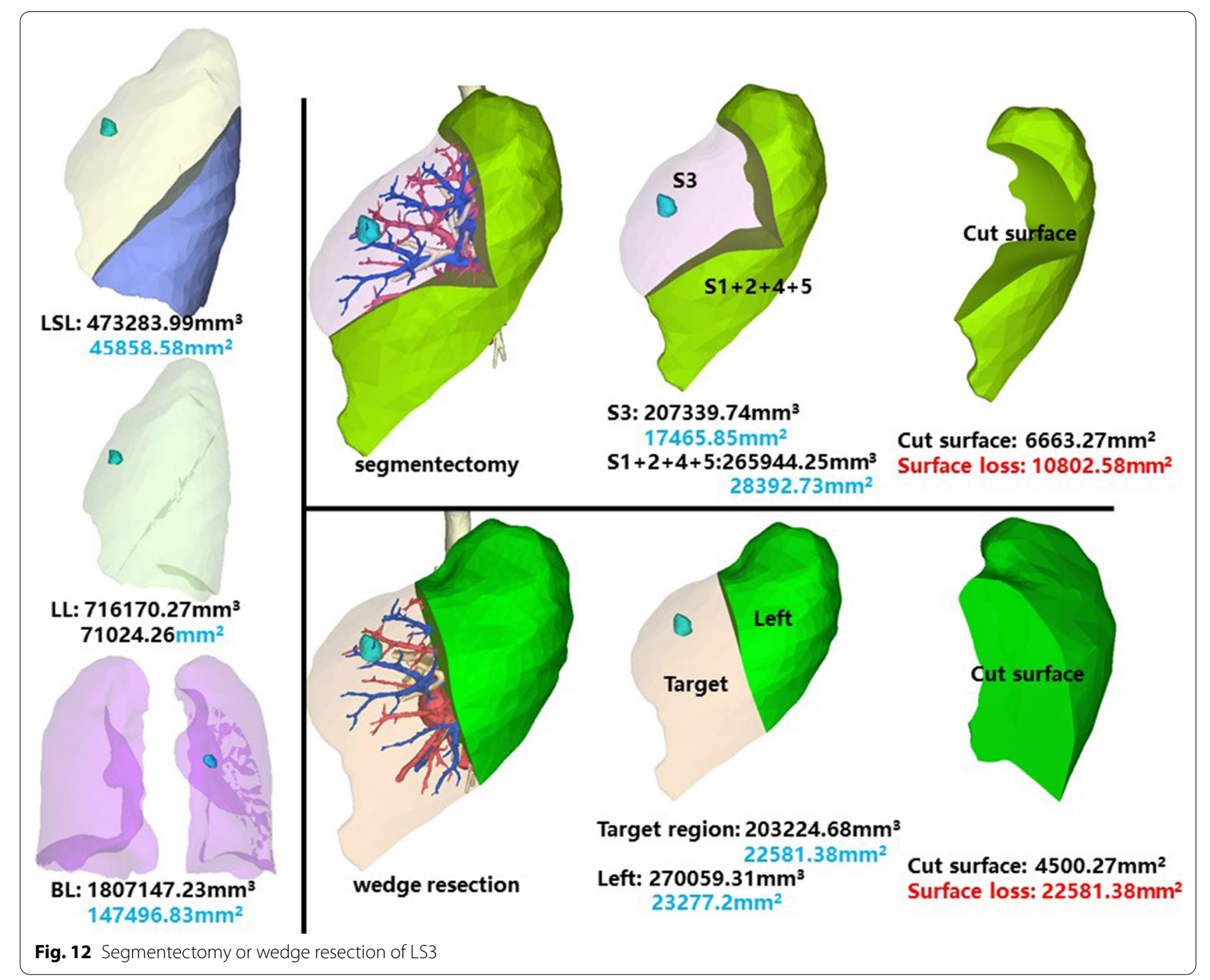




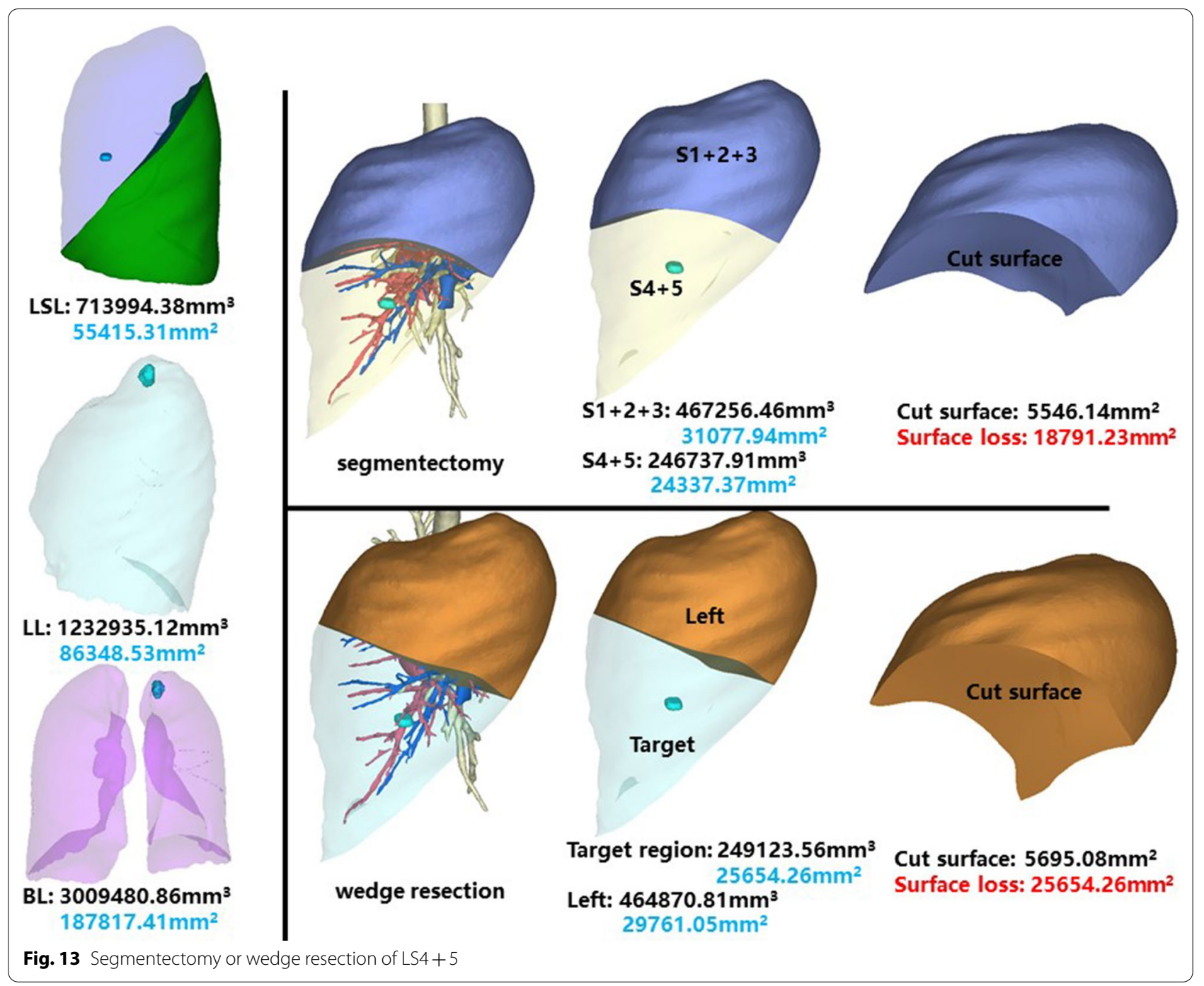




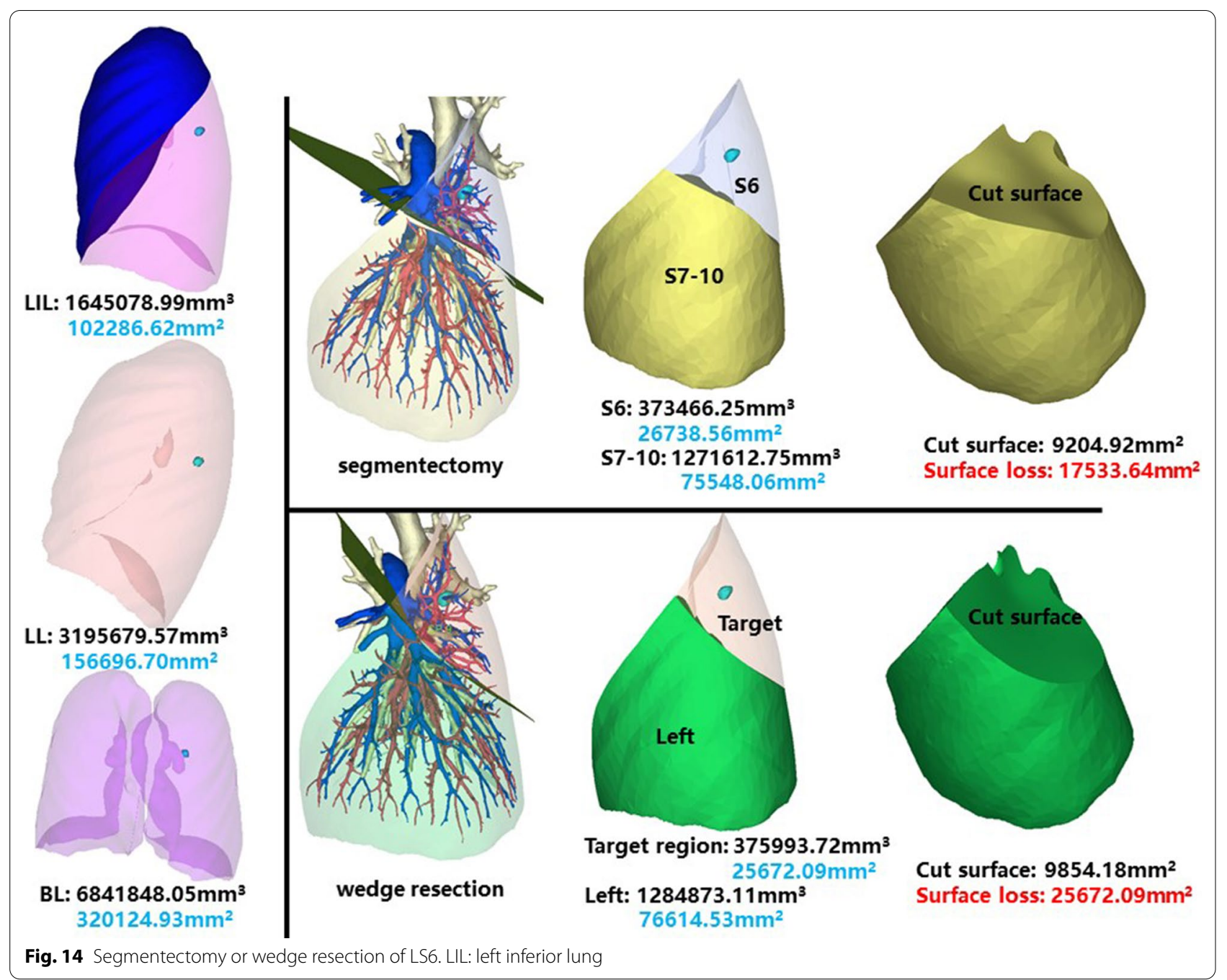




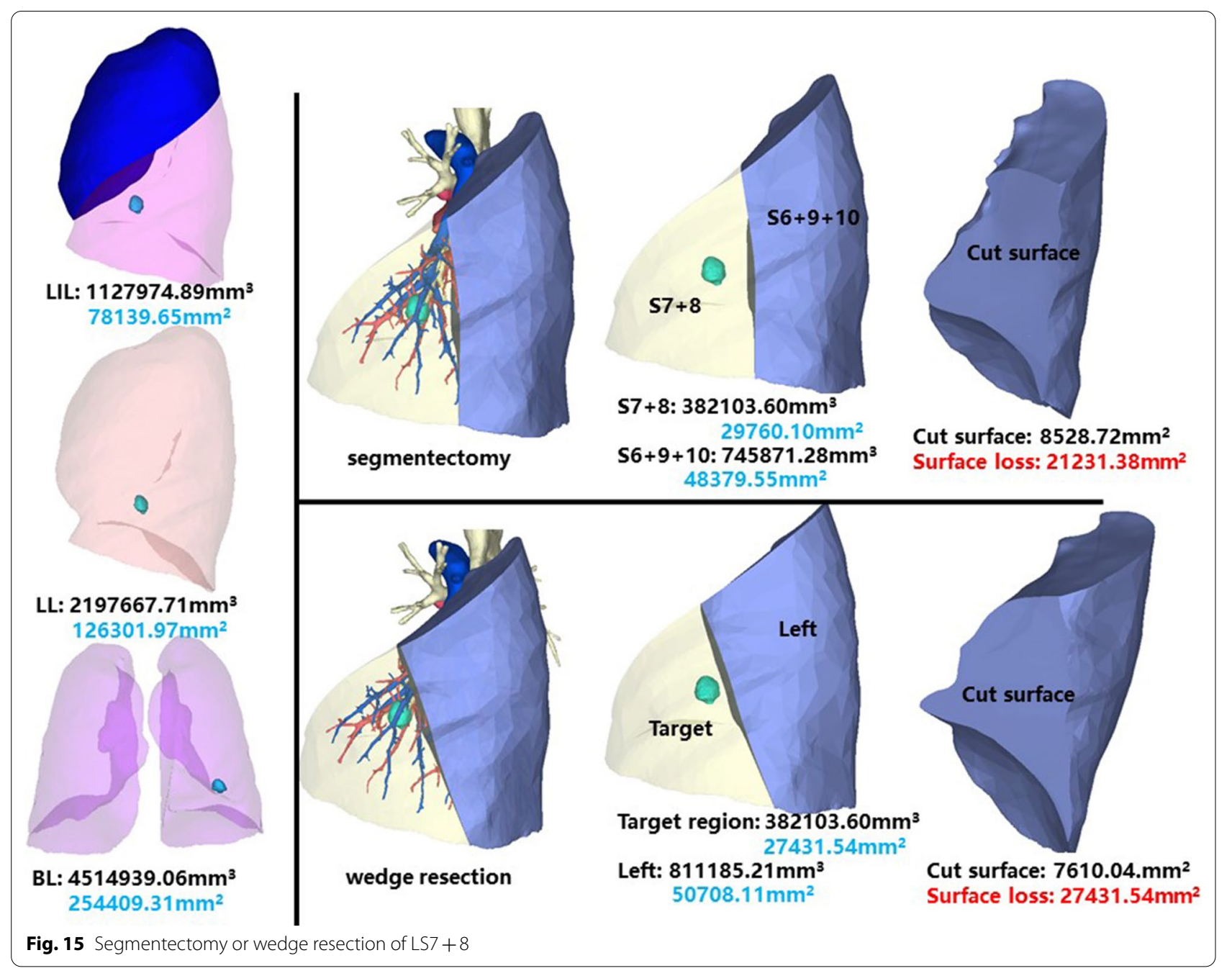




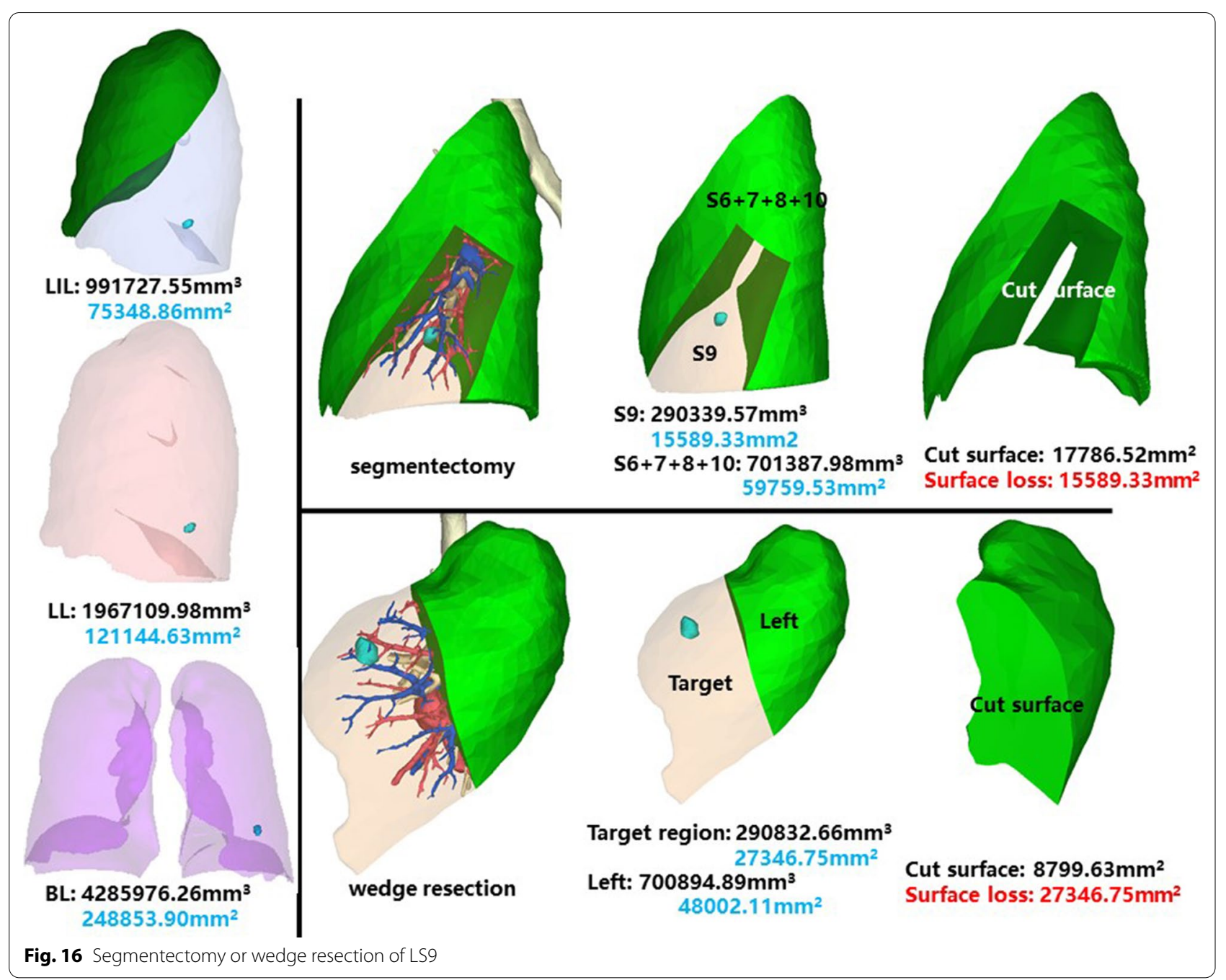




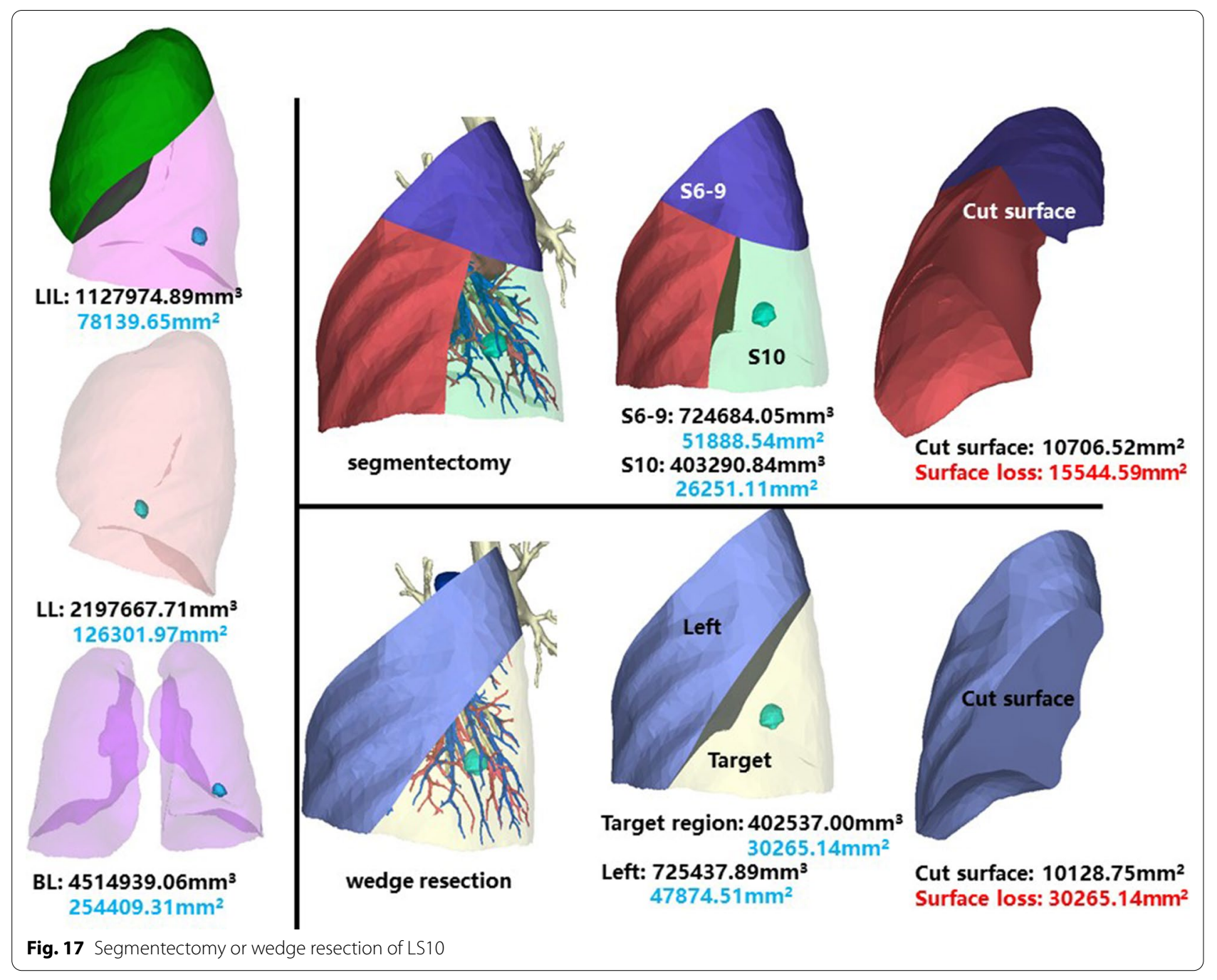


Table 1 The surface loss of all segments after segmentectomy and wedge resection, and their difference

\begin{tabular}{llllll}
\hline Segment & $\begin{array}{l}\text { Total pulmonary } \\
\text { surface area }\left(\mathbf{m m}^{2}\right)\end{array}$ & $\begin{array}{l}\text { Surface loss of } \\
\text { segmentectomy }\left(\mathbf{m m}^{2}\right)\end{array}$ & $\begin{array}{l}\text { Surface loss of wedge } \\
\text { resection }\left(\mathbf{m m}^{2}\right)\end{array}$ & $\begin{array}{l}\text { Difference value } \\
\left(\mathbf{m m}^{2}\right)\end{array}$ & $\begin{array}{l}\text { Difference value/total } \\
\text { pulmonary surface area } \\
\text { (\%) }\end{array}$ \\
\hline RS4 & $254,751.29$ & $12,356.17$ & $15,503.65$ & 3147.48 & 1.24 \\
RS5 & $253,657.46$ & $16,348.54$ & $20,586.35$ & 4237.81 & 1.67 \\
LS1 +2 & $241,265.57$ & $15,214.75$ & $19,632.18$ & 4417.43 & 1.83 \\
LS7+8 & $268,562.24$ & $23,451.58$ & $28,412.68$ & 4961.1 & 1.85 \\
LS6 & $271,421.32$ & $14,971.07$ & $21,751.2$ & 6780.13 & 2.50 \\
RS6 & $238,895.42$ & $14,542.49$ & $21,256.85$ & 6714.36 & 2.81 \\
RS3 & $241,235.59$ & $14,582.27$ & $21,473.56$ & 6891.29 & 2.86 \\
RS1 & $256,916.43$ & 6428.45 & $14,304.08$ & 7875.63 & 3.07 \\
LS4+5 & $249,867.79$ & $22,461.04$ & $30,466.32$ & 8005.28 & 3.20 \\
RS2 & $245,876.66$ & 7005.53 & $15,861.24$ & 8855.71 & 3.60 \\
LS9 & $265,233.24$ & $16,231.25$ & $26,351.85$ & $10,120.6$ & 3.82 \\
RS9 & $266,705.61$ & $11,481.47$ & $22,744.04$ & $11,262.57$ & 4.22 \\
LS10 & $274,456.43$ & $14,566.02$ & $27,970.87$ & $13,404.85$ & 4.88 \\
LS3 & $236,481.09$ & $14,928.14$ & $28,601.18$ & $13,673.04$ & 5.78 \\
RS10 & $261,171.69$ & 5268.19 & $21,127.29$ & $15,859.1$ & 6.07 \\
RS7 & $274,986.12$ & 4896.48 & $21,669.6$ & $16,773.12$ & 6.10 \\
RS8 & $228,569.78$ & $11,356.23$ & $25,523.52$ & $14,167.29$ & 6.20 \\
\hline
\end{tabular}

\section{Abbreviations}

GGO: Ground-glass opacities; CT: Computed tomography; AAH: Atypical adenomatous hyperplasia; AIS: Adenocarcinoma in situ; MIA: Or malignancies such as minimally invasive adenocarcinoma; LPA: Lepidic-predominant invasive adenocarcinomas; NCCN: National Comprehensive Cancer Network; NSCLC: Non-small-cell lung cancer; OS: Overall survival; DFS: Disease-free survival.

\section{Acknowledgements}

None declared.

\section{Authors' contributions}

TL undertook the work of three-dimensional rebuilding of computed tomography (CT) images. QC undertook the work of writing the manuscript. JZ made substantial contributions to conception and design the study. LC helped to collect the CT images. XH helped to collect the CT images. All authors read and approved the final manuscript.

\section{Funding}

Not applicable.

\section{Availability of data and materials}

All data is contained within the manuscript and its additional files.

\section{Declarations}

Ethics approval and consent to participate

Not applicable.

\section{Consent for publication}

Written informed consent was routinely obtained from every patients before surgery resection, that they agree to use their clinical data in medical study.

\section{Competing interests}

The authors declare that they have no competing interests.

\section{Author details}

${ }^{1}$ Department of Thoracic Surgery, Cancer Hospital of The University of Chinese Academy of Sciences (Zhejiang Cancer Hospital), 1\# East Banshan Road, Hangzhou 310022, Zhejiang, China. ${ }^{2}$ Institute of Cancer and Basic Medicine (IBMC),

Chinese Academy of Sciences, Hangzhou, Zhejiang, China.

Received: 23 May 2021 Accepted: 3 August 2021

Published online: 14 September 2021

\section{References}

1. Sihoe ADL, Hiranandani R, Wong H, Yeung ESL. Operating on a suspicious lung mass without a pre-operative tissue diagnosis: pros and cons. Eur J Cardiothorac Surg. 2013;44(2):231-7.

2. Lee HJ, Lee CH, Jeong YJ, et al. IASLC/ATS/ERS international multidisciplinary classification of lung adenocarcinoma: novel concepts and radiologic implications. J Thorac Imaging. 2012;27(6):340-53.

3. Collins J, Stern EJ. Ground-glass opacity at CT: the ABCs. Am J Roentgenol. 1997;169(2):355-67.

4. Gao JW, Rizzo S, Ma LH, Qiu XY, Warth A, et al. Pulmonary ground-glass opacity: computed tomography features, histopathology and molecular pathology. Transl Lung Cancer Res. 2017;6(1):68-75.

5. Gould MK, Donington J, Lynch WR, Mazzone PJ, Midthun DE, Naidich DP, et al. Evaluation of individuals with pulmonary nodules: when is it lung cancer? Diagnosis and management of lung cancer, 3rd ed: American College of Chest Physicians evidence-based clinical practice guidelines. Chest. 2013;143(5 Suppl):e93S-120S.

6. Wood DE, Kazerooni EA, Baum SL, Eapen GA, Ettinger DS, et al. Lung cancer screening, Version 3.2018, NCCN clinical practice guidelines in oncology. J Natl Compr Canc Netw. 2018;16(4):412-41.

7. Reveliotis K, Kalavrouziotis G, Skevis K, Charpidou A, Trigidou R, et al. Wedge resection and segmentectomy in patients with stage I non-small cell lung carcinoma. Oncol Rev. 2014;8(2):234.

8. Tsutani Y, Kagimoto A, Handa Y, Mimae T, Miyata Y, et al. Wedge resection versus segmentectomy in patients with stage I non-small-cell lung cancer unfit for lobectomy. Jpn J Clin Oncol. 2019;49(12):1134-42. 
9. Zhang H, Liu C, Tan Z, Zhang T. Segmentectomy versus wedge resection for stage I non-small cell lung cancer: a meta-analysis. J Surg Res. 2019;243:371-9.

10. Ginsberg RJ, Rubinstein LV. Randomized trial of lobectomy versus limited resection of T1NO non-small-cell lung cancer. Lung Cancer Study Group. Ann Thorac Surg. 1995;60(3):615-23.

11. Landreneau RJ, Sugarbaker DJ, Mack MJ, et al. Wedge resection versus lobectomy for stage I (T1NOMO) non-samll-cell lung cancer. J Thorac Cardiovasc Surg. 1997;113(4):691-700.

\section{Publisher's Note}

Springer Nature remains neutral with regard to jurisdictional claims in published maps and institutional affiliations.
Ready to submit your research? Choose BMC and benefit from:

- fast, convenient online submission

- thorough peer review by experienced researchers in your field

- rapid publication on acceptance

- support for research data, including large and complex data types

- gold Open Access which fosters wider collaboration and increased citations

- maximum visibility for your research: over 100M website views per year

At BMC, research is always in progress.

Learn more biomedcentral.com/submissions 